$\$$ sciendo

\title{
Georges Rey, Emoções e Funcionalismo: em Defesa do Cognitivismo
}

\author{
Isabel Góis \\ King's College London
}

Disputatio No. 4

May 1998

DOI: $10.2478 /$ disp-1998-0003

ISSN: 0873-626X 


\title{
GEORGES REY, EMOÇÕES E FUNCIONALISMO: EM DEFESA DO COGNITIVISMO
}

\author{
Isabel Góis ${ }^{1}$
}

\section{Introdução}

Poucas histórias de ficção científica escapam à tentação de descrever máquinas que exibem um repertório de comportamentos inteligentes que hoje reservamos apenas para seres humanos. Os exemplos são inúmeros e vão desde o terrível Big Brother de 1984, passando pelas versões mais ou menos hilariantes dos robôs de A Guerra das Estrelas, até ao muito sofisticado e discutido HAL de 2001 - Odisseia no Espaço. Evidentemente, todas estas máquinas são ficções e podemos tratar a metáfora de estados mentais nestes contextos com mais ou menos literalidade. Contudo, quando colocamos a questão de saber se tais engenhos são realizáveis, a possibilidade de os desenvolvimentos da inteligência artificial poderem vir um dia a apresentar-nos máquinas que, além de pensantes e conversadoras, têm também sonhos (ambições e desejos acerca do futuro) e emoções, parece a alguns necessariamente subverter a ideia de um «eu» afectivo e moralmente responsável, características que fazem de nós não apenas máquinas pensantes, mas sobretudo pessoas.

O problema de fundo cobre obviamente uma vasta e intrincada área de argumentação e parece-nos de um optimismo ingénuo julgar que podemos pensar todas as questões por ele levantadas em termos de uma resposta a uma única pergunta: «Podem ou não as máquinas vir a ser pessoas?» $\mathrm{O}$ tema pode ser apresentado de maneiras distintas, algumas bastante específicas, e nada garante que formular a comparação implica a existência de um único sentido do termo «pessoa» ou um significado preferível a que todas as abor-

\footnotetext{
${ }^{1}$ Este estudo foi realizado com o apoio de uma bolsa gentilmente concedida pela JNICT, no âmbito do programa Práxis XXI.
}

\section{Disputatio 4 (1998)}


dagens possíveis dão o seu assentimento. Contudo, não nos parece demasiada ousadia afirmar que a ideia de que chips e outros componentes informáticos são simplesmente inapropriados e impermeáveis a emoções, constitui certamente uma das razões mais fortes pelas quais muitos resistem à possibilidade de um mecanismo computacional, para além de poder replicar as operações «racionais» da mente, poder vir também a ter experiências afectivas e, por conseguinte, apresentar as emoções moralmente relevantes (por exemplo, arrependimento) para a atribuição do estatuto de pessoa. Brincando um pouco com os termos do argumento, poderíamos dizer que aquilo que desafia as intuições mais comuns acerca da equiparação de máquinas a pessoas é imaginar onde é que aquelas sentem. Afinal, nós sentimos «na carne» o que é estar triste, irritar-se, ter medo, orgulho, compadecer-se, amar, desejar; mas as máquinas parecem ser demasiado «artificiais» para haver algo nelas que marque uma diferença entre a expressão «a frio» ou «a quente» de uma emoção. Neste sentido, as emoções parecem constituir um desafio especial aos modelos computacionais da mente.

Não é nosso desejo discutir aqui as condições debaixo das quais é ou não apropriado atribuir o estatuto de «pessoa» ou de «responsabilidade moral»a máquinas, nem tão pouco fazer exercícios de futurologia quanto à possibilidade de um dia estas virem realmente a ser emocionais ou não. A nossa abordagem a este tema concentra-se antes no sentido de argumentar contra a tese de que há qualquer coisa de especial acerca das emoções que as coloca fora do alcance do poder explicativo de um funcionalismo computacionalista. Em particular, o objectivo que nos move é o de disputar o argumento de Georges Rey, apresentado num artigo intitulado «Functionalism and Emotions» (Rey, 1980) acerca do papel e natureza das emoções e contestar a sua tese de que as conclusões aí ensaiadas nos levam a restringir as pretensões de uma visão funcionalista da mente.

A nossa discussão terá os seguintes momentos: em primeiro lugar, analisaremos as considerações levantadas pelo autor acerca da implausibilidade de uma descrição funcionalista das emoções, nomeadamente na sua variante cognitivista. Seguidamente, a nossa atenção recairá sobre a resposta de Rey à pergunta «Debaixo de que condições é que um fenómeno $x$ é uma emoção?» Aqui, pretendemos, sobretudo, questionar se o uso ou referência de conceitos relativos a emoções convoca uma linha de explicação distinta daquela que é utilizada para outros processos cognitivos. $\mathrm{O}$ alvo da nossa argumentação é a tese defendida pelo autor de que podemos estar dispostos a 
aceitar que é possível construir um computador que realiza todas as funções cognitivas dos cérebros e, ainda assim, resistir a atribuir-lhe sentimentos e, daí, o estatuto de pessoa moral, pela razão única que essas emoções não são produzidas (causadas) pelo mesmo tipo de estados internos que em nós. A conclusão que pretendemos estabelecer é a de que as considerações levadas a cabo por Georges Rey acerca da natureza e papel das emoções, não só não estabelecem a tese por ele enunciada, como assentam numa análise pouco convincente do que podemos e devemos saber acerca da atribuição de emoções, quer a pessoas, quer a máquinas. Terminaremos com algumas observações relativas ao significado desta acusação para a plausibilidade de uma abordagem cognitivista das emoções.

I

Posta em termos muito gerais, a tese funcionalista acerca da mente é a de que cada tipo de estado mental é idêntico à função causal que ele tipicamente desempenha e cuja descrição é fisicamente neutra. Que esta formulação pareça demasiado abstracta não é apenas consequência de a pretendermos apresentar em termos suficientemente vagos para ser aceite por todas as variedades de sensibilidades funcionalistas. Um dos objectivos programáticos de base do funcionalismo é precisamente o de desafiar a ideia de que a natureza dos estados mentais está intrinsecamente ligada ao suporte físico que os realiza e, nessa medida, o carácter abstracto da definição visa deixar bem claro que para um funcionalista não faz grande diferença se o sistema a que está a atribuir mentalidade é feito de células nervosas, tubos de vácuo ou latas de conserva - desde que cumpra o papel causal especificado pela função, exemplifica as propriedades mentais.

Tipicamente, a reaç̧ão à tese funcionalista defende que se trata de uma extravagância que ou peca por excesso, ou por defeito; isto é, ou atribui estados mentais a entidades que (obviamente) os não têm, ou nega «mentalidade» a outras que não teríamos dúvidas a possuem. Ned Block vai mais longe e afirma mesmo que o funcionalismo, por princípio, não pode escapar a ser, ao mesmo tempo, demasiado liberal e demasiado chauvinista nas suas atribuições de estados mentais - exactamente aqueles pecados do fisicalismo e do behaviourismo que era suposto redimir.

Muitas versões de funcionalismo têm sido formuladas na tentativa de responder a esta e outras críticas e, salutarmente, nem todas as versões dessa 
tese passam ilesas à bateria de objecções levantadas contra elas. Georges Rey, em particular, acredita que o funcionalismo computacionalista-cognitivista é inadequado a uma completa caracterização de fenómenos psicológicos e defende uma aproximação do funcionalismo às teses mais tradicionais do fisicalismo. Como poderá esta aproximação não equivaler a minar de base o funcionalismo não nos é dito; mas Rey acredita sem dúvida que há estados mentais, nomeadamente as emoções, que são impenetráveis a uma análise cognitiva. Uma vez que estas constituem um dado central da experiência humana, qualquer teoria da mente que se mostre incapaz de dar resposta à questão «Que tipo de fenómeno são as emoções?», estará inevitavelmente condenada a não crescer à altura do título que se arroga.

Parece-nos óbvio que o lugar natural para começarmos a responder a esta pergunta é examinar se o cognitivismo leva ou não demasiado longe a ideia de que a mente pode ser comparada a um programa e o cérebro a um computador. Justamente, uma premissa maior do cognitivismo é a de que, uma vez que a invenção dos computadores demonstra que muitos dos processos a que chamamos pensamento podem ocorrer em suportes completamente distintos do humano, então, a haver identidade, ela não é entre um estado mental e um estado físico do sistema onde ele tem lugar, mas sim ao nível dos objectivos da actividade cognitiva, dos processos nela envolvidos, nos meios de avaliação desses processos, etc. A mente pode, assim, ser comparada a um programa e o cérebro a um computador, com a vantagem de podermos perfeitamente falar de estados mentais e de uns estados mentais causarem outros, sem ter de identificar esses estados com a classe de acontecimentos físicos que com eles se correlacionam. É claro que nos seres humanos os estados mentais são (eventualmente idênticos a) estados cerebrais, mas, para um cognitivista, tal não só não significa que tenhamos de reduzir as explicações psicológicas a explicações neurofisiológicas, como menos ainda que essa é a maneira mais adequada de dar conta da «mentalidade» de um sistema.

Um dos modelos mais populares da tese computacionalista é certamente a chamada máquina universal de Turing, a qual sugere que um conjunto de regras codificadas internamente e demarcando um âmbito de operações possíveis, pode resultar numa variedade infinita de respostas à manipulação dos seus comandos. A noção tem tanto de simples como, aparentemente, de aterrador: tudo o que precisamos de imaginar é uma máquina munida de um scanner por onde passa uma fita impressa de comprimento variável e que 
manipula símbolos de acordo com regras precisas representadas pelos controlos do engenho. Estes consistem em quatro operações: I) a máquina lê o símbolo $x$ impresso na fita; II) verifica o estado actual dos controlos; III) imprime um novo símbolo; IV) avança um espaço na fita para a direita ou para a esquerda. As transições de estado da máquina podem ser traduzidas por uma função (finitamente especificada) e a cartografia dos inputs (dados de entrada) e outputs (dados de saída) computada pelo engenho é definida pelo conjunto binário de sequências impressas na fita, respectivamente antes e depois da computação.

Duas consequências importantes se seguem: em primeiro lugar, a máquina de Turing assegura que a capacidade de computação depende inteiramente do poder de processamento de estados semanticamente interpretáveis dentro do próprio modelo e não da quantidade de informação externa. Quer dizer, o que é crucial na computação é a classe de operações possíveis que um sistema pode executar e as funções que ele leva a cabo, ou seja, a capacidade de um dado sistema para interpretar um símbolo à luz de outros símbolos e de os ligar da maneira apropriada ao conjunto de acções possíveis dentro do sistema.

Uma segunda consequência é a de que, desde que sejamos capazes de especificar os passos necessários à execução de um qualquer objectivo num código binário (por exemplo, zeros e uns), então qualquer sistema que leve a cabo esse programa poderia ser entendido como uma realização da máquina de Turing. Diz a tradição que a especificação desse programa pode ser conseguida recorrendo a algoritmos. Estes consistem, como se deixa entrever pela descrição da máquina de Turing, numa série de passos distintamente definidos e «evidentes». A verificarem-se, estas duas consequências confirmariam as teses computacionalistas de que um estado mental se define pelo seu papel causal (função) e de que a computação é um processo mecânico, independente do suporte físico e deve ser descrito em termos puramente formais.

Assim, afirmar que o cérebro se assemelha, por analogia, a um computador é mais do que a simples adopção, mais ou menos metafórica, dos modelos sofisticados da inteligência artificial. Ou seja, não se trata apenas de dizer que, uma vez que podemos simular mecanicamente uma série de processos mentais, isto é, uma vez que podemos dizer que (algumas) máquinas têm objectivos, raciocinam, transformam informação, revêem as suas estratégias, então os humanos podem também ser caracterizados da mesma ma- 
neira. A tese forte que alicerça tal analogia é a de que o que a mente humana literalmente faz é computar e que todas as operações cognitivas devem ser descritas em termos de processos computacionais.

Com efeito, apesar de muitos críticos do computacionalismo tenderem a ignorá-lo, o que a analogia sugere não é que os cérebros imitam os computadores a nível fisiológico, ou que os neurónios emitem sinapses em «zeros» e «uns». Bem pelo contrário, o que é proposto é exactamente que a maneira correcta de caracterizar toda a cognição, humana ou não, é fazê-lo a um nível mais elevado do que o dos materiais que a suportam, sejam estes estruturas e mecanismos do sistema nervoso ou componentes informáticos; por outras palavras, a analogia estabelece-se ao nível do tipo de operações mentais envolvidas na cognição humana, nomeadamente aquelas relativas a processos de decisão e as estratégias incorporadas num programa de computador. A proposta substancial do computacionalismo é a de que esse nível é o de formas de representação mental, postulando entidades teóricas como ideias, símbolos, regras, imagens e descrevendo as estruturas e processos pelos quais estas representações se combinam, transformam e contrastam entre si. A assumpção de fundo suposta na analogia é, por conseguinte, a de que essas estruturas e processos devem ser vistos como um conjunto de regras e proposições (por exemplo, crenças e objectivos) simbolicamente incorporadas no material de suporte e as suas operações vistas à luz dos princípios da inferência racional.

Embora desenvolvimentos posteriores das ciências cognitivas tenham vindo a questionar e rever muita da interpretação a dar às teses acima enunciadas, é inegável que grande parte da resistência ao computacionalismo cognitivista se centra na plausibilidade de postular um nível representacional para falar acerca de estados mentais. Este conceito serve o propósito de assentar as regras de interpretação de estados mentais e, por conseguinte, legitimar as descrições dos mesmos, pelo que está destinado a ser alvo de polémica. Para um funcionalista, o conceito tem, obviamente, a vantagem de não nos obrigar a tomar posição acerca do tipo de correlação — se necessária ou contingente - entre acontecimentos mentais e acontecimentos físicos e, nesse sentido, dispensa-nos de qualquer compromisso ontológico acerca da referência de termos como «crenças» e «desejos». Ou seja, um estado mental é inteiramente individuado pelo seu papel causal na rede de crenças e objectivos incorporados num sistema e isso é tudo o que há de relevante a dizer. Nem todos, contudo, acreditam que o assunto fique resolvido só assim. 
De uma maneira geral, as objecções contra os modelos computacionais da mente seguem duas vias: por um lado, evocam a redução ilegítima de estados mentais a operações puramente algorítmicas (baseadas em regras de manipulação de símbolos) e questionam a «realidade» do mental assim produzido; por outro, alegam que esses modelos são demasiado abstractos para poderem fornecer um modelo cabalmente explicativo da mente. Basicamente o que aqui está em causa não é tanto dizer que as condições para atribuir a um sistema um dado estado mental, dependem de esse estado ser causado pelo tipo apropriado de processos internos, mas o que devemos interpretar como processos internos apropriados e em que circunstâncias.

Precisamente o que muitos filósofos contestam é que condições puramente computacionais, mesmo que suficientes para definir o que é ter uma determinada crença ou desejo específico, sejam só por si suficientes para dar conta do que é ter um certo estado mental ou estar num certo estado mental. Rey, mais concretamente, está disposto a aceitar que o funcionalismo computacionalista dá conta de muitas das propriedades do mental, nomeadamente daquela que tem sido reputada de mais importante - a intencionalidade, e inclusivamente, que o permite fazer de uma maneira totalmente representacional e mecânica - através de algoritmos. Contudo, recusa que as emoções possam ser analisadas a um nível estritamente cognitivo (representacional) e, nessa medida, que o computacionalismo puro seja uma teoria psicológica completa. Para o autor, só os estados físicos do sistema nervoso têm a propriedade de definir estados emocionais. A «certeza» que espreita por detrás destas objecções é a de que seguramente o mental, mesmo que seja também isso, não é só isso - alguma coisa mais tem de haver, se não uma propriedade insondável, certamente um atributo identificável do nosso sistema nervoso.

Se Rey tem razão, uma consequência a tirar daí, aliás muito desejada por todos os críticos do funcionalismo, seria certamente a de que, pelo menos certos processos mentais são necessariamente processos físicos, isto é, oferta exclusiva do sistema nervoso. Outra consequência, não menos importante, seria a de que as nossas análises do mental deveriam permitir-nos passar directamente da nossa linguagem comum acerca de desejos, intenções, crenças e planos para a «linguagem» do sistema nervoso: afinal de contas, é aí que tudo se passa. Mas se Rey não nos tiver dado razões suficientes para acreditar que as emoções são, de facto, impermeáveis a uma abordagem cognitivista, então, não só as emoções não nos obrigam a invocar outra linha de 
descrição de processos mentais, como nada têm de especial que desafie as pretensões do funcionalismo computacionalista-cognitivista. (O bónus da disputa está, sem dúvida, em saber se teremos ou não um dia de tratar os computadores como pessoas e preocupar-nos com os seus sentimentos.) A questão que nos guia agora é, portanto, a de saber se as nossas atribuições de emoções excluem ou não a possibilidade de «máquinas pensantes» virem a ter emoções.

II

Comecemos por imaginar que um qualquer cientista, num acto de arrebatamento criativo, construía um robô exteriormente indistinguível de um ser humano e o programava de maneira a exibir um repertório considerável de crenças, intenções e preferências. Podemos mesmo imaginar que esse robô é capaz de ter crenças e desejos acerca de crenças e desejos: o programa nele implantado poderia perfeitamente ser dotado de recursividade, o qual lhe permitiria ter intenções de segunda ordem e mesmo desejos acerca de crenças e crenças acerca de desejos. Agora suponhamos que, enganados pela aparência da máquina e durante amena conversa com o autómato, este nos dizia: «Sinto que qualquer coisa de terrível está para acontecer.» Seguramente, não hesitaríamos em interpretar tal expressão como angústia, ou seja, em atribuir-lhe uma emoção. A questão é: que tipo de suposições sustentam a nossa atribuição desta emoção ao sujeito que a profere?

A resposta que ocorre de imediato é a de que estamos a supor que o nosso interlocutor acredita que alguma coisa de terrível está para acontecer. Por outras palavras, supomos que o nosso interlocutor não só acredita que alguma coisa pode de facto acontecer, mas também que é terrível, que ele deseja que não aconteça e que o não pode evitar. Mas o que esta resposta sugere é que ter (sentir) uma emoção é o mesmo que assumir uma determinada atitude para com uma proposição, nomeadamente a de que a proposição é verdadeira. No caso do robô, certamente não teria sido difícil ao cientista programar o autómato para gerar crenças baseado na avaliação do tipo de input que entra no sistema de computação. A hipótese, de resto, e como vimos, cabe no modelo da máquina de Turing: basta que o programa represente um domínio de acções possíveis e faça as inferências adequadas acerca da informação que lhe é dada. A única condição é que esta seja semanticamente interpretável dentro do sistema, ou seja, que o input represente qualquer coisa 
para o próprio robô. Neste caso, uma emoção poderia ser definida como uma implicação acerca de uma proposição; no nosso exemplo, a implicação de que o robô acredita que é vulnerável a um perigo eminente.

Quer isto dizer que ele está angustiado porque tem esta crença, ou que tem esta crença porque está angustiado e, então, o uso do termo refere-se a outra coisa ainda? Por outras palavras, é a crença que causa a emoção, ou não podemos apropriadamente chamar «causas» às crenças? Se respondermos que sim à primeira parte da ambas as questões, como estamos convictos que o devemos fazer, então seguir os processos cognitivos apropriados (crença + avaliação + implicação + desejo), é suficiente para ter emoções. O cognitivista pode reclamar os «louros» da disputa e afirmar que responde aos dois desafios mais importantes acerca das emoções: descrevê-las em termos puramente computacionais e apontar qual o papel da cognição na origem e individuação dos afectos. É isto quanto baste para entendermos a natureza das emoções? Mais, obtemos esta análise de todas as emoções?

Afinal, as nossas experiências emocionais incluem estados que vão desde sensações básicas, puramente «qualitativas» (por exemplo, a sensação de alarme ao ouvir um som intenso e súbito), até sentimentos com um conteúdo intencional bastante complexo (por exemplo, embaraço, gratidão ou devoção patriótica), pelo que a pergunta naturalmente se impõe: «Sob que condições dizemos que um fenómeno $x$ é uma emoção?» Para um cognitivista, como vimos, a resposta a esta pergunta tem a forma de uma explicação em termos dos processos de decisão que o sistema de que estamos a falar leva a cabo para resolver as tarefas para que está programado. Isto é, em termos das crenças e objectivos representados no conjunto de processos algorítmicos nele incorporados, na exacta medida em que estes determinam o conteúdo de um estado mental pela função específica que ele desempenha. Neste sentido, os estados emocionais nada têm de especial que desafie a tese cognitivista: uma emoção é apenas a função que resulta da maneira como um input afecta um sistema. Como tal, descrevemo-la nos mesmos termos representacionais (crenças, desejos, objectivos, planos, intenções) que utilizamos para qualquer outro estado mental, sem nada atender ao material que as suporta.

A objecção de Rey não se faz esperar: as emoções até podem ser semelhantes a outros estados mentais, ter um conteúdo intencional e serem determináveis intensionalmente, mas sentimo-las de maneira diferente. Logo, o material de suporte não é irrelevante e não nos podemos abstrair das suas propriedades quando definimos o que conta para atribuir a um estado mental 
a distinção de ser um estado emocional: um robô não sente nos seus componentes informáticos o que é estar ansioso para dar um salto de pára-quedas. Por outras palavras, para lhe ser atribuída uma emoção, não basta a um sujeito ter as crenças apropriadas e fazer as inferências adequadas; ele tem também de ter músculos, nervos e um sistema endócrino, e as suas glândulas têm de disparar as hormonas e os neuroreguladores certos para que esse estado mental seja, por exemplo, alegria quando o seu atleta de boxe favorito ganha o título de campeão.

A tese de Rey é a de que as emoções são processos nomológicos complexos entre cognições e estados fisiológicos e que só os estados internos do nosso sistema neuroregulador são apropriados para definir uma emoção como esta ou aquela emoção específica. A conclusão que extrai daqui é a de que nenhuma análise cognitiva pode esgotar as atribuições de estados emocionais, por ser cega à condição necessária e suficiente mais importante: a nossa fisiologia. A consequência inevitável desta posição é a de que a nossa psicologia se exprimiria em termos, mais ou menos, como estes: «Sempre que o neurónio $x$ dispara o neurotransmissor $y$, Maria sente-se apaixonada».

Esta tese, contudo, merece-nos três linhas de objecção: em primeiro lugar, mesmo que venhamos um dia a conhecer detalhadamente o nosso sistema nervoso, é de duvidar que encontremos aí o momento preciso em que uma emoção é gerada, seja ela a dor mais penetrante e súbita ou o sentimento mais elaborado. A dificuldade que se coloca não tem o carácter vago de dizer que olhando para um cérebro, não conseguimos descobrir onde está o prazer de alguém em ouvir uma ópera. Antes, aquilo a que se apela com a objecção é ao facto de os mesmos acontecimentos físicos poderem e, realmente, servirem de suporte a estados mentais, e especialmente a emoções, completamente distintos. Logo, não são suficientes para distinguir nem esta emoção de outra, nem diferentes exemplares do mesmo tipo de emoção. $\mathrm{O}$ caso do medo parece-nos clássico: alterações do ritmo cardíaco, libertação de adrenalina e secreções hormonais podem dar-nos a indicação do tipo de estado em que um indivíduo (pessoa ou não) se encontra; mas se não adoptarmos o nível das representações mentais, não só nunca chegaremos a saber acerca do quê, nem porquê, nem se é realmente medo ou, suponha-se, ansiedade. Mais, se não tivermos em conta o contexto intensional e intencional em que um dado estímulo é representado, nunca conseguiremos determinar se essas «sensações» são um prazer ou um desprazer. Para ver a diferença, 
basta pensarmos o que seria o medo de levar um tiro durante um assalto e o mesmo medo durante uma brincadeira de «polícias e ladrões».

Uma segunda linha de objecção segue-se directamente da primeira e prende-se com uma confusão que nos parece estar por detrás da tese de Rey: a de pensar que o nosso uso e referência de conceitos para emoções nos permite estabelecer leis, ou seja, condições necessárias e suficientes, para identificar termos para estados emocionais com termos para estados do sistema nervoso. $\mathrm{O}$ resultado desta confusão é que o autor simplesmente ignora, primeiro, que termos para emoções não podem ser substituídos salva affecttione: as emoções são necessariamente intencionais, pelo que uma diferença no seu objecto equivale a uma diferença no seu conteúdo; segundo, que elas não só são activadas cognitivamente, como podem ser modificadas pelos processos representacionais de um indivíduo, como as suas outras crenças e desejos. Logo, qualquer relação entre emoções e estados endócrinos parece-nos meramente contingente.

Uma última linha de objecção diz respeito à conclusão que parece seguir-se da tese de Rey: a de que o nosso sistema neuroregulador é feito para nos fazer sentir medo e não para predispor os nossos corpos a lidar eficazmente com ameaças. Se isto for verdade, quer dizer que os nossos cérebros se «acenderam» um dia já capazes de se comoverem ao ouvir as Variações de Goldberg ou a sentirem orgulho, remorso, compaixão, arrependimento, amor ou mesmo de negar qualquer um destes sentimentos. Mas a hipótese é, no mínimo, implausível: nem o nosso sistema neuroregulador é biologicamente adaptado às múltiplas experiências que provocam em nós emoções, nem nós, humanos, nascemos com um repertório fixo de estados emocionais. Aprendemos a sentir, o que sentir, quando sentir e a interpretar sentimentos, não só através da nossa experiência interpessoal, como do percurso formativo/cultural que fazemos. Posto por outras palavras, aprendemos a ter certas atitudes para com determinadas proposições: a acreditar que são verdadeiras ou falsas, a inferir que implicam certas outras proposições, a desejar que sejam verdadeiras ou falsas. Por isso, mesmo a «linguagem» das emoções é a das crenças, intenções, desejos, planos, preferências e não a dos neurotransmissores e glândulas endócrinas.

Assim, e tendo em conta as considerações anteriores, podemos concluir que não só as emoções não são impenetráveis a uma análise cognitiva, como parece ser neste contexto que melhor se faz notar a necessidade de postular 
um nível representacional. O resumo do nosso argumento é que as emoções, no caso típico, são activadas cognitivamente, são estados cognitivos e devem ser descritas em termos de crenças e desejos. Logo, nem nos parece que as emoções constituam especial desafio às pretensões do computacionalista-cognitivista, nem que coloquem qualquer imperativo materialista à tese de base do funcionalismo. É certo que, subjectivamente, as emoções parecem ser diferentes de outros estados mentais, mas é plausível pensar-se que seja assim precisamente porque os processos cognitivos envolvidos nos estados emocionais reflectem, por excelência, padrões individuais de associar um input a um output, ou seja as regularidades funcionais da nossa cognição. Além disso, as emoções estão directamente implicadas na acção (presente, passada e futura), o que as torna particularmente importantes quando temos de resolver problemas e tomar decisões.

Quer isto dizer que as máquinas, para além de pensadoras, podem realmente vir a sentir? Teremos de esperar e ver. Mas, quer venham ou não a exibir emoções, ainda assim algo de estranho se passa com a afirmação de Rey de que, mesmo que o venham a fazer, não teremos de as tratar como pessoas porque essas emoções não são produzidas pelos mesmos estados internos que em nós. Ao invés, o autor perguntava-nos se estaríamos dispostos a dizer que um engenho feito do que quer que seja pode ter emoções e é uma pessoa só porque tem as suas «partes» organizadas da maneira apropriada e só porque os seus estados internos cumprem o papel causal atribuído a estados mentais. Contudo, face ao que acima fica dito, podemos devolver a interrogação a Rey e perguntar se estamos dispostos a dizer que o amor que a Maria sente por alguém é só um disparo neuronal e glandular. ${ }^{2}$

\section{Isabel Góis}

Dept. of Philosophy, King's College London

Strand, London WC2R 2LS, UK

isabel.gois@kcl.ac.uk

\footnotetext{
${ }^{2}$ Agradeço os valiosos comentários de João Branquinho e Fernando Ferreira, cuja orientação, conselhos e comentários contribuíram em muito para o estudo aqui apresentado. Devo também um especial agradecimento a Carlos João Correia pelas inúmeras discussões que tivemos sobre filosofia da mente e cuja oposição às teses que aqui defendo foi sempre um estímulo para encontrar mais e melhores argumentos.
} 


\section{Referências}

Averill, J. (1980) «Emotion and Anxiety: Sociocultural, Biological, and Psychological Determinants» in Rorty, A., org., Explaining Emotions. California: University of California Press, pp. 37-72

Block, N. (1992) «Troubles with Functionalism» in Beakley, B. \& Ludlow, P., orgs., The Philosophy of Mind: Classical Problems, Contemporary Issues. Cambridge, Mass.: MIT Press, pp. 69-90

LeDoux, J. (1996) «In Search of an Emotional System in the Brain: Leaping from Fear to Emotion and Consciousness» in Gazzaniga, M., org., The Cognitive Neurosciences. Cambridge, Mass.: Bradford, pp. 1049-1062

Dennett, D. (1978) «Why You Can't Make a Computer that Feels Pain» in Brainstorms. Cambridge, Mass.: MIT Press, pp. 190-229

Dennett, D. (1978) «Conditions of Personhood» in Brainstorms. Cambridge, Mass.: MIT Press, pp. 267-285

Dennett, D. (1978) «Reply to Arbib and Gunderson» in Brainstorms. Cambridge, Mass.: MIT Press, pp. 23-38

Dennett, D. (1995) Darwin's Dangerous Idea. New York: Touchstone

Halgren, E. e Marinkovic, K. (1996) «Neurophysiological Networks Integrating Human Emotions» in Gazzaniga, M., org., The Cognitive Neurosciences. Cambridge, Mass.: Bradford, pp. 1137-1152

McEwen, B. (1996) «Stressful Experience, Brain and Emotions: Developmental, Genetic, and Hormonal Influences» in Gazzaniga, M., org., The Cognitive Neurosciences. Cambridge, Mass.: Bradford, pp. 1117-1136

Rolls, E. T. (1996) «A Theory of Emotion and Consciousness, and Its Application to Understanding the Neural Basis of Emotion» in Gazzaniga, M., org., The Cognitive Neurosciences. Cambridge, Mass.: Bradford, pp. 1091-1106.

Rey, G. (1980) «Functionalism and Emotions» in Rorty, A., org., Explaining Emotions. California: University of California Press, pp. 152-163.

Rorty, A. (1980) «Explaining Emotions» in Rorty, A., org., Explaining Emotions. California: University of California Press, pp. 103-126.

de Sousa, R. (1980) «The Rationality of Emotions» in Rorty, A., org., Explaining Emotions. University of California Press, pp. 127-152.

Teasdale, J. e Barnard, P. (1993) Affect, Cognition and Change: remodelling depressive thought. Trowbridge: Lawrence Erlbaum Associates. 